\title{
Two pathogenic mutations located within the 5'-regulatory sequence of the GJB1 gene affecting initiation of transcription and translation
}

\author{
Dagmara Kabzińska ${ }^{1 凶}$, Katarzyna Kotruchow ${ }^{1}$, Barbara Ryniewicz² and Andrzej Kochański ${ }^{1}$ \\ 1Neuromuscular Unit, Mossakowski Medical Research Centre, Polish Academy of Sciences, Warszawa, Poland; 2 Department of Neurology, Medi- \\ cal University of Warszawa, Warsaw, Poland
}

\begin{abstract}
In contrast to mutations in the coding sequences of a genes involved in the pathogenesis of Charcot-MarieTooth disease (CMT), little is known about CMT phenotypes resulting from a DNA variants located in regulatory sequences of a given " CMT gene". Charcot-MarieTooth type X1 disease (CMTX1) is caused by mutations in the GJB1 gene coding for an ion channel known as connexin, with a molecular mass of $32 \mathrm{kDa}$ (Cx32). Only $0.01 \%$ of the GJB1 gene mutations have been reported in its $5^{\prime}$ regulatory sequence. Pathogenic mutations occured in the internal ribosome entry site (IRES) are extremely rarely reported in human genetic disorders. To the best of our knowledge, in this study we report for the first time in an Eastern European population, two CMTX1 families in which two pathogenic mutations in the $5^{\prime}$ regulatory sequence of the GJB1 gene (c. $-529 T>C$ and $-459 C>T$ ) have been found. The two mutations identified in our study disturb the $5^{\prime}$ UTR sequence in two different ways, by affecting the transcription factor SOX10 binding site (c. $-529 T>C)$ and by the disrupting IRES element of GJB1 gene (c. $-459 \mathrm{C}>\mathrm{T}$ ). These regions are responsible for transcription (SOX10) and initiation of translation (IRES), respectively. On the basis of our findings that, in contrast to the most DNA sequence variants reported in untranslated regulatory regions of genes, the c. $-459 \mathrm{C}>\mathrm{T}$ and c. $-529 \mathrm{~T}>\mathrm{C}$ mutations remain pathogenic in the context of different ethnic background.
\end{abstract}

Keywords: mutations in regulatory elements, GJB1 gene, IRES element, transcription, translation

Received: 04 March, 2011; revised: 06 April, 2011; accepted: 12 September, 2011; available on-line: 14 September, 2011

\section{INTRODUCTION}

Charcot-Marie-Tooth disease (CMT) is one of the most heterogeneous human heritable neuromuscular disorders with a very complex classification. CMT prevalence has been estimated at 1 in 2500 (Skre, 1974). Recent investigations in the Norwegian population estimated CMT prevalence at 1 per 1214, while other epidemiological studies in Spain, Italy, Iceland and Japan gave estimates ranging from 1 in 3500 to 1 in 9200. CharcotMarie-Tooth type X-linked disease (CMTX1) linked to mutations in the GJB1/C 32 gene (gap junction protein, beta 1 /connexin 32 ) belongs to the most frequent CMT forms with the prevalence of $4.1 \%$ to $9.8 \%$, depending on particular CMT patient population (Braathen et al.,
2011). CMT1X is an X-linked dominant disease, with males being generally more affected than females. Phenotype in males ranges from moderate to severe, while women are in most cases only mildly affected or even asymptomatic (Kleopa \& Scherer, 2006).

Since the initial linkage studies of the CMT1X in 1978 and 1982 (de Weerdt, 1978; Iselius \& Grimby, 1982) and description of families with mutations in the GJB1 gene (Bergoffen et al., 1993) over 300 different pathogenic mutations in this gene have been reported (IPNMD, PubMed). Most mutations in the GJB1 have been found in the coding region of the gene, including nonsense and missense mutations, deletions, insertions and frameshifts. Merely eight sequence variants including six pathogenic mutations and one unclear variant have been described in a non-coding region comprising gene promoter 2 ( $\mathrm{Ta}$ ble 1) [IPNMD, PubMed]. The GJB1 gene contains two alternative promoters, $\mathrm{P} 1$ and $\mathrm{P} 2$, responsible for expression in different tissues. The Cx32 transcript (variant 1) in the peripheral nervous system is mainly initiated by the P2 promoter, while promoter P1 is responsible for expression of transcripts (variant 2) in the liver, pancreas, oocytes and embryonic stem cells. On the other hand, transcripts initiated in the central nervous system use both P1 and P2 promoters (Fig. 1) (Neuhaus et al., 1995; 1996; Söhl et al., 2001). The most prominent transcription factors of the GJB1 gene expressed in myelinating Schwann cells are EGR2 and SOX10 (Kuhlbrodt et al., 1998; Warner et al., 1998). EGR2 and SOX10 mutations have prominent influence on the expression of the GJB1 gene (Bondurand et al., 2001) and these mutations are associated with CMT1D and Waardenburg syndrome type 4C, respectively (Pingault et al., 1998; Warner et al., 1998). Such non-coding mutations can strongly affect translation of the GJB1 gene via an IRES-dependent mechanism, which is the next level of expression modulation. The internal ribosome entry site (IRES) is a

e-mail: dagkab@cmdik.pan.pl

Abbreviations: GJB1/Cx32, gap junction protein beta 1/connexin 32; IRES, internal ribosome entry site; CMT, Charcot-Marie-Tooth disease; CMTX1, Charcot-Marie-Tooth type X1; SOX10, SRY-box 10; IPNMD, Inherited Peripheral Neuropathies Mutation Database; EGR2, early growth response 2; CMT1D, Charcot-Marie-Tooth type 1D; $5^{\prime}$ UTR, $5^{\prime}$ untranslated region of RNA; ITAFs, IRES, specific cellular trans-acting factors; RQ-PCR, real-time PCR; SSCP, single strand conformation polymorphism; HA, heteroduplex analysis; PMP22, peripheral myelin protein 22; FANCC, Fanconi anemia, complementation group C; FA, Fanconi anemia; IVS4, intron 4; LITAF, lipopolysaccharide-induced TNF factor; CMT1C, Charcot-Marie-Tooth type 1C; PubMed, database of references and abstracts on life sciences and biomedical topics 
Table 1. Mutations in the promoter region of the GJB1 gene reported in 1996-2010

\begin{tabular}{|c|c|c|c|}
\hline \multicolumn{2}{|c|}{ Mutations in the GJB1 gene promoter region } & \multirow{2}{*}{ Phenotype } & \multirow{2}{*}{ Citations } \\
\hline Original paper numbering & Standardized numbering & & \\
\hline c. $-215 \mathrm{G}>\mathrm{A}$ & c. $-713 \mathrm{G}>\mathrm{A}$ & CMTX1/polymorphism & $\begin{array}{l}\text { Wang et al., 2000, } \\
\text { Bergmann et al., } 2001\end{array}$ \\
\hline$c-529 \mathrm{~T}>\mathrm{C}$ & c. $-529 \mathrm{~T}>\mathrm{C}$ & CMTX1 & Beauvais et al., 2006 \\
\hline c. $-528 \mathrm{~T}>\mathrm{G}$ & c. $-529 \mathrm{~T}>\mathrm{G}$ & CMTX1 & lonasescu et al., 1996 \\
\hline c. $-526 \mathrm{G}>\mathrm{C}$ & c. $-527 \mathrm{G}>\mathrm{C}$ & CMTX1 & Houlden et al., 2004 \\
\hline c. $-458 \mathrm{C}>\mathrm{T}$ & c. -459 C>T & CMTX1 & lonasescu et al., 1996 \\
\hline c. $-458 \mathrm{G}>\mathrm{A}$ & c. $-458 \mathrm{G}>\mathrm{A}$ & polymorphism & Bergmann et al., 2002 \\
\hline c. $-373 \mathrm{G}>\mathrm{A}$ & c. $-373 \mathrm{G}>\mathrm{A}$ & CMTX1 & Murphy et al., 2010 \\
\hline c. $-215 \mathrm{G}>\mathrm{A}$ & c. $-215 \mathrm{G}>\mathrm{A}$ & CMTX1 & Wu et al., 2004 \\
\hline
\end{tabular}

CMTX1, Charcot-Marie-Tooth disease X-linked type 1. Original paper numbering, mutation numbers used in original papers based on previous reference sequence. Standardized numbering, mutation numbers according to current reference sequence.

highly structured mRNA sequence in the 5' untranslated region of RNA (5' UTR), which recruits, among others, IRES-specific cellular trans-acting factors (ITAFs), RNAbinding proteins needed to start or enhance translation. The presence of IRES elements within the 5'-regulatory sequence of a gene indicates that translation of its mRNA may be conducted via an alternative molecular mechanism that does not depend on the cap structure on the 5'-end of the mRNA (Baird et al., 2006).

In this study, we report two Polish CMTX families in which two pathogenic mutations, c. $-529 \mathrm{~T}>\mathrm{C}$ and c. $-459 \mathrm{C}>\mathrm{T}$, were found for the first time in an Eastern European population.

\section{MATERIALS AND METHODS}

Molecular genetic studies. DNA from peripheral blood from six family members (II:6, III:1 from fam- ily 1; and I:1, III:4, III:5 and IV:2 from the family 2) was screened for duplication and deletion of the PMP22 (peripheral myelin protein 22) gene using real-time quantitative polymerase chain reaction (RQ-PCR) (Aarskog \& Vedeler, 2000). Reference values for the dosage of PMP22 gene of healthy individuals (two copies of PMP22 gene) range between 0.700 and 1.090. Values below 0.600 indicate a heterozygous deletion of the PMP22 gene, and those above 1.180 indicate duplication (Kabzińska et al., 2009). The whole coding sequence of PMP22 gene was screened using single strand conformation polymorphism (SSCP) and heteroduplex analysis (HA), and the coding sequence plus 754 nucleotides upstream of ATG codon of the GJB1 gene was sequenced directly. The primers used, were designed by Bergoffen et al. (1993).

Sequencing of the promoter of the GJB1 gene in those families was done after a detailed family data analysis on the basis of the following: (i) pedigree analysis

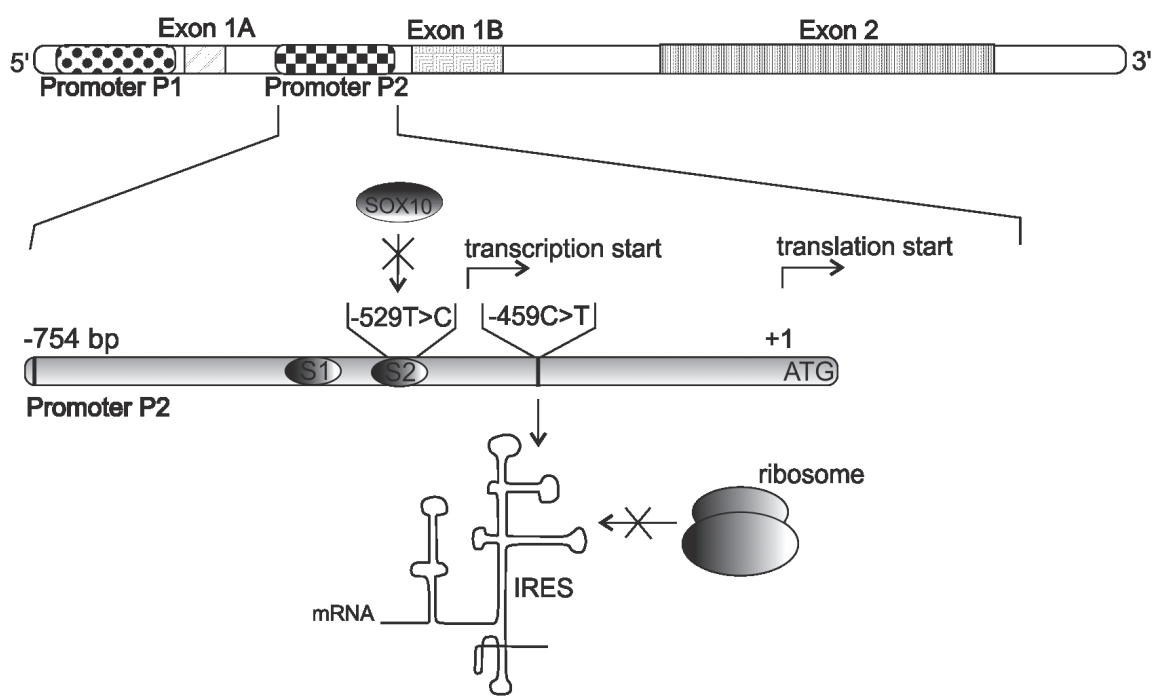

Figure 1. Two mutations located in the $5^{\prime}$ regulatory sequence of the GJB1 gene (P2 promoter) act in two independent ways The $-529 \mathrm{~T}>\mathrm{C}$ mutation in the S2 binding site for the transcription factor SOX10 abolishes SOX10 binding, which impairs transcription of the GJB1 gene. The $-459 C>$ T mutation in the IRES element impairs binding of the small subunit of the ribosome with IRES and in this way leads to impaired translation of the GJB1 mRNA. The region analyzed encompasses $754 \mathrm{bp}$ in the $5^{\prime}$ regulatory region of the GJB1 gene. 
indicated possible X-linked mode of inheritance, (ii) the clinical course of CMT was milder in affected women than in affected men and (iii) no mutations were found in the coding sequence of the GJB1 gene.

\section{RESULTS}

\section{Family reports}

The affected members of the first family included the proband (14-year-old boy) and his 33-year-old mother (Fig. 2). The proband (III:1) was born by cesarean section following a normal pregnancy, with the birth weight of $2600 \mathrm{~g}$, and scored 9 points in the Apgar scale. He could sit at 6 months and walk at about 18 months. Walking disturbances and progressive foot deformity appeared at approximately 7 years of age. He was admitted to our neurological department in 2006. We found distal muscle atrophy, absent knee and ankle jerks, slight distal paresis in legs without any sensory deficit and feet deformity. The mother of the proband (II:6) was considered to be healthy but she showed slight foot deformity and ankle jerks. ENG was performed in the patient and his mother. In the proband, we found axonal changes with CV slowing (about $31-36 \mathrm{~m} / \mathrm{s}$ in the median and peroneal nerves) and low response amplitude (below $1.0 \mathrm{mV}$ ), and chronic neurogenic changes in the tibial muscle. Similar changes were found in the ENG in the mother of the proband. In both examinations, slight demyelinating changes were present, especially distal latency prolongation.

The second family consisted of four generations in which three individuals have been found to be as af-

a)

Family 1

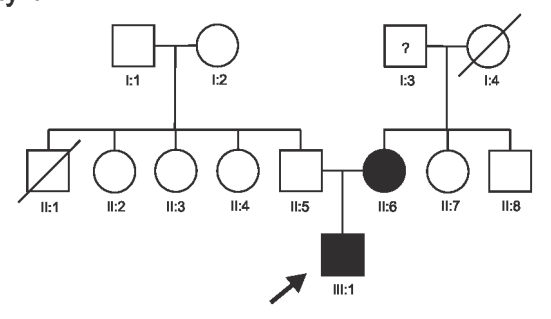

c)

Family 2

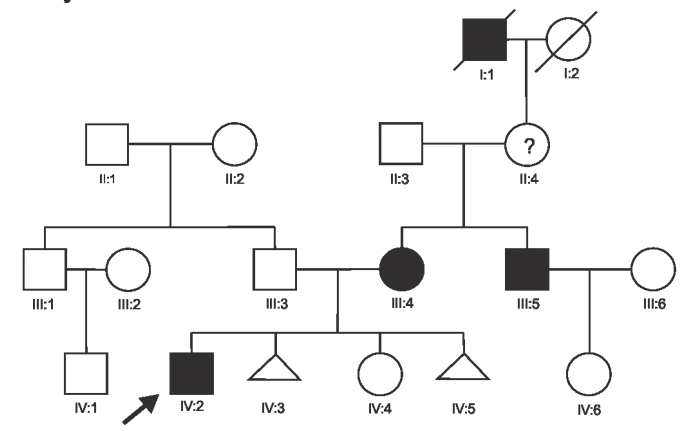

fected (Fig. 2): the proband, his mother and his uncle. The status of individual II:4 could not be verified by us, however, due to the rules of X-dominant inheritance, the grandmother of the proband had to be affected. No male to male transmission of CMT disease was observed in this family. Clinical, electrophysiological and genetic evaluation was available in proband (IV:2) and his mother (III:4). The proband, 21-year-old university student, had slight distal paresis of the small hand muscles. He was unable to walk on his heels. The ankle jerk was weak on the left side and absent on the right side. He also showed foot drop on the right side. Additionally, he showed mild sensory disturbances in the distal parts of the lower and upper limbs. The mother of the proband, aged 44 years, was previously considered a healthy woman. In neurological examination, she was able to walk on her toes but could not walk on her feet. She had mild pes cavus deformity, and the ankle jerks were weak. The uncle of the proband (III:5), aged 45 years, was also affected with CMT. He showed symmetrical distal weakness and atrophy in the upper and lower limbs (Fig. 2).

\section{Molecular genetic findings}

Duplication or deletion of the PMP22 gene as well as mutations in the coding regions of the PMP22 and GJB1 genes were excluded. The values of the PMP22 gene dosage in the DNA samples from individuals examined ranged from 0.799 to 0.874 . Direct sequencing of the $754 \mathrm{bp}$ promoter region of the GJB1 gene in family 1 revealed a $\mathrm{T}$ to $\mathrm{C}$ transition at the nucleotide -529 (relative to the ATG start codon) in the proband (III:1) and his mother (II:6), located in the S2 binding site of SOX10 within the P2 promoter region. In family 2, a b)

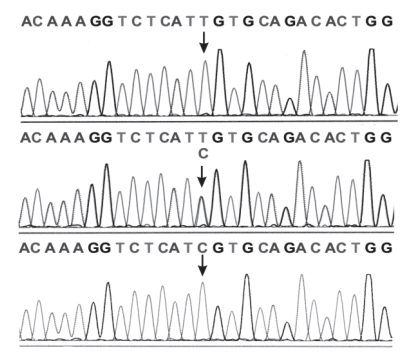

d)
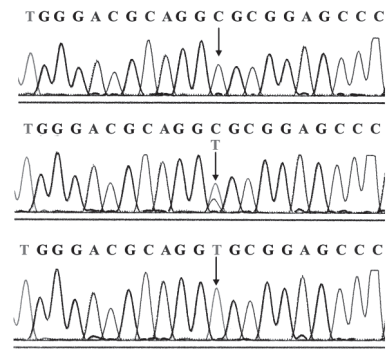

Figure 2. Family trees for the $-529 \mathrm{~T}>\mathrm{C}$ (Family 1 ) and $-459 \mathrm{C}>\mathrm{T}$ (Family 2) mutations in the $5^{\prime}$ regulatory sequence of the GJB1 gene The probands are marked with arrows. Open symbols indicate healthy males (squares) and females (circles). Filled symbols correspond to affected individuals. Deceased individuals are marked with diagonal lines. Triangles represent spontaneous miscarriages. a) pedigree of the first family, b) chromatograms showing the base pair -529 (marked with an arrow) of a healthy individual (top), heterozygote (middle) and hemizygote (bottom) c) pedigree of the second family, d) chromatograms showing the base pair -459 (marked with an arrow) of a healthy individual (top), the heterozygote (middle) and hemizygote (bottom). 
$\mathrm{C}$ to $\mathrm{T}$ transition at the nucleotide -459 (relative to the ATG start codon) was found in the three individuals (proband, mother and uncle) in the IRES (Internal Ribosome Entry Site) element in the P2 region.

\section{DISCUSSION}

In the standard molecular genetic approach to CMT, molecular analysis is limited to the coding region of a gene. Thus, due to the lack of a systematic analysis of the regulatory sequences of the CMT genes it is impossible accurately to estimate the impact of mutations located in the regulatory region of the GJB1 gene on the etiology of CMT1X disease. In fact, of the hundreds of mutations reported to date in the GJB1 gene, only eight have been identified in its regulatory sequence (IPNMD).

In our study, we decided to analyze the $5^{\prime}$ regulatory sequence of the GJB1 gene due to the absence of any mutations in the coding region of the GJB1 gene in the two families with a mode of inheritance typical for X-dominant disorders, and an observed discrepancy between the classical CMTX1 phenotype in affected males and a mild clinical course of CMTX1 in affected females. Thus, our study illustrates the importance of the phenotype-genotype correlations in the direction of molecular diagnosis of CMT.

To the best of our knowledge, this is the first raport of two mutations in the $5^{\prime}$ regulatory sequence of the GJB1 gene in an Eastern European population. We found a c. $-459 \mathrm{C}>\mathrm{T}$ mutation in three related members of the CMTX1 family that segregated with the disease phenotype. Interestingly, the c. $-459 \mathrm{C}>\mathrm{T}$ mutation which was previously reported in ethnically divergent populations (Italy, United States and Hong Kong) also segregated with the CMTX1 phenotype (Ionasescu et al., 1996; Flagiello et al., 1998, Li et al., 2009). The results of our study show that the pathogenic status of the c. $-459 \mathrm{C}>\mathrm{T}$ mutation does not depend on the ethnic background. Notably, the IVS4+4 A to T transition in the FANCC gene was initially thought to be limited to the Ashkenazi Jewish population and to segregate with a severe phenotype of the Fanconi anemia (FA) (Whitney, et al., 1993). The same IVS4+4 A>T mutation in the FANCC gene occurring in the Japanese population is not associated with a severe phenotype of Fanconi anemia, and the clinical symptoms of FA in patients harboring IVS4+4 A>T mutation do not differ from those in patients with other mutations in the FANCC gene (Futaki et al., 2000).

The second mutation in the $5^{\prime}$ regulatory region of the GJB1 gene reported by us, c. $-529 \mathrm{~T}>\mathrm{C}$, also seems not to be dependent on the ethnic background, since it has been previously reported in the French population (Beauvais et al., 2006). In contrast to the $-459 \mathrm{C}>\mathrm{T}$ mutation, the c. $-529 \mathrm{~T}>\mathrm{C}$ mutation cosegregated with the T49M mutation in the LITAF gene which may be causative for the CMT1C disease (Saifi et al., 2005; Beavuais et al., 2006). Thus, there is evidence that the c.-459C $>\mathrm{T}$ mutation is more pathogenic than the $-529 \mathrm{~T}>\mathrm{C}$ sequence variant.

The two GJB1 promoter mutations reported in this study act via two independent molecular mechanisms. The $-529 \mathrm{~T}>\mathrm{C}$ mutation is located within a binding site (S2) of the transcription factor SOX10. Transcription efficiency of the GJB1 gene has been reported to be regulated by the SOX10 and EGR2 transcription factors. In an elegant study, Houlden and colleagues (2004) provided evidence for decreased transcription of the GJB1 gene harboring the $-529 \mathrm{~T}>\mathrm{C}$ sequence variant. The molecular mechanism of the $-459 \mathrm{C}>\mathrm{T}$ mutation affects expression is extremely rarely encountered in human pathology. Internal ribosome entry sites (IRES) are well characterized in bacteria and viruses, but so far no mutations within IRES elements have been detected in human disorders. Therefore, the presence of mutations in the IRES elements of the GJB1 gene suggests that similar pathogenic mutations in other human genes are likely to be discoverd (Macejak \& Sarnow, 1991). Hudder and Werner (2004) provided evidence that the $-459 \mathrm{C}>\mathrm{T}$ mutation located in the IRES region of the GJB1 gene abolishes its translation at an early phase (initiation).

To conclude, in our study we reported two CMTX1 families in which two mutations in the 5 ' regulatory sequence of the GJB1 gene were found. Due to the segregation of the GJB1 sequence variants with the CMTX1 phenotype and complete penetrance of these mutations in different populations, we assume that these mutations located in the regulatory region of the GJB1 gene may be classified as pathogenic.

\section{Acknowledgements}

We dedicate this study to our Colleague Dr. Halina Strugalska-Cynowska who died in 2009. The authors thank Profesor Ewa Bartnik for valuable advice during preparation of this manuscript. The authors are grateful to Mrs Jadwiga Kędzierska and Mrs Izabela Podstawka for skillful technical assistance.

This study was supported by a grant from the Ministry of Science and Higher Education No. NN. 402 276336 to A.K.

\section{REFERENCES}

Aarskog NK, Vedeler CA (2000) Real-time quantitative polymerase chain reaction. A new method that detects both the peripheral myelin protein 22 duplication in Charcot-Marie-Tooth type 1A disease and the peripheral myelin protein 22 deletion in hereditary neuropathy with liability to pressure palsies. Hum Genet 107: 494-498.

Baird SD, Turcotte M, Korneluk RG, Holcik M (2006) Searching for IRES. RNA 12: 1755-1785.

Beauvais K, Furby A, Latour P (2006) Clinical, electrophysiological and molecular genetic studies in a family with X-linked dominant Charcot-Marie-Tooth neuropathy presenting a novel mutation in GJB1 promoter and a rare polymorphism in LITAF/SIMPLE. Neuromuscul Disord 16: 14-18.

Bergoffen J, Scherer SS, Wang S, Scott MO, Bone LJ, Paul DL, Chen K, Lensch MW, Chance PF, Fischbeck KH (1993) Connexin mutations in X-linked Charcot-Marie-Tooth disease. Science 262: 20392042.

Bondurand N, Girard M, Pingault V, Lemort N, Dubourg O, Goossens M (2001) Human connexin 32, a gap junction protein altered in the X-linked form of Charcot-Marie-Tooth disease, is directly regulated by the transcription factor SOX10. Hum Mol Genet 10: 2783-2795.

Braathen GJ, Sand JC, Lobato A, Høyer H, Russell MB (2011) Genetic epidemiology of Charcot-Marie-Tooth in the general population. Eur J Neurol 18: 39-48.

de Weerdt CJ (1978) Charcot-Marie-Tooth disease with sex-linked inheritance, linkage studies and abnormal serum alkaline phosphatase levels. Eur Neurol 17: 336-344.

Flagiello L, Cirigliano V, Strazzullo M, Cappa V, Ciccodicola A, D'Esposito M, Torrente I, Werner R, Di Iorio G, Rinaldi M, Dallapiccola A, Forabosco A, Ventruto V, D'Urso M (1998) Mutation in the nerve-specific 5' non-coding region of Cx32 gene and absence of specific mRNA in a CMTX1 Italian family. Mutations in brief no. 195. Online. Hum Mutat 12: 361.

Futaki M, Yamashita T, Yagasaki H, Toda T, Yabe M, Kato S, Asano S, Nakahata T (2000) The IVS4 + 4 A to T mutation of the Fanconi anemia gene FANCC is not associated with a severe phenotype in Japanese patients. Blood 95: 1493-1498.

Houlden H, Girard M, Cockerell C, Ingram D, Wood NW, Goossens M, Walker RW, Reilly MM (2004) Connexin 32 promoter P2 mutations: a mechanism of peripheral nerve dysfunction. Ann Neurol 56: $730-734$. 
Hudder A, Werner R (2000) Analysis of a Charcot-Marie-Tooth disease mutation reveals an essential internal ribosome entry site element in the connexin-32 gene. J Biol Chem 275: 34586-34591.

Ionasescu VV, Searby C, Ionasescu R, Neuhaus IM, Werner R (1996) Mutations of the noncoding region of the connexin32 gene in $\mathrm{X}$ linked dominant Charcot-Marie-Tooth neuropathy. Neurology 47: 541-544.

IPNMD http: //www.molgen.ua.ac.be/cmtmutations/Mutations/Mutations.cfm

Iselius L, Grimby L (1982) A family with Charcot-Marie-Tooth's disease, showing a probable X-linked incompletely dominant inheritance. Hereditas 97: 157-158.

Kabzińska D, Pierscinska J, Kochański A (2009) Screening of the 17 p11.2-p12 region in a large kohort of patients with CharcotMarie-Tooth (CMT) disease or hereditary neuropathy with liability to pressure palsies (HNPP). J Appl Genetics 50: 283-288.

Kleopa KA, Scherer SS (2006) Molecular genetics of X-linked CharcotMarie-Tooth disease. Neuromolecular Med 8: 107-122.

Kuhlbrodt K, Herbarth B, Sock E, Hermans-Borgmeyer I, Wegner M (1998) Sox10, a novel transcriptional modulator in glial cells. J Neurosci 18: 237-250.

Li M, Cheng TS, Ho PW, Chan KH, Mak W, Cheung RT, Ramsden DB, Sham PC, Song Y, Ho SL (2009) $-459 \mathrm{C}>\mathrm{T}$ point mutation in 5 ' non-coding region of human GJB1 gene is linked to X-linked Charcot-Marie-Tooth neuropathy. J Peripher Nerv Syst 14: 14-21.

Macejak DG, Sarnow P (1991) Internal initiation of translation mediated by the 5' leader of a cellular mRNA. Nature 353: 90-94.

Neuhaus IM, Bone L, Wang S, Ionasescu V, Werner R (1996) The human connexin 32 gene is transcribed from two tissue-specific promoters. Biosci Rep 16: 239-248.
Neuhaus IM, Dahl G, Werner R (1995) Use of alternate promoters for tissue-specific expression of the gene coding for connexin32. Gene 158: $257-262$.

Pingault V, Bondurand N, Kuhlbrodt K, Goerich DE, Préhu MO, Puliti A, Herbarth B, Hermans-Borgmeyer I, Legius E, Matthijs G, Amiel J, Lyonnet S, Ceccherini I, Romeo G, Smith JC, Read AP, Wegner M, Goossens M (1998) SOX10 mutations in patients with Waardenburg-Hirschsprung disease. Nat Genet 18: 171-173.

Saifi GM, Szigeti K, Wiszniewski W, Shy ME, Krajewski K, Hausmanowa-Petrusewicz I, Kochanski A, Reeser S, Mancias P, Butler I, Lupski JR (2005) SIMPLE mutations in Charcot-Marie-Tooth disease and the potential role of its protein product in protein degradation. Hum Mutat 25: 372-383.

Skre H (1974) Genetic and clinical aspects of Charcot-Marie-Tooth's disease. Clin Genet 6: 98-118.

Söhl G, Theis M, Hallas G, Brambach S, Dahl E, Kidder G, Willecke K (2001) A new alternatively spliced transcript of the mouse connexin32 gene is expressed in embryonic stem cells, oocytes, and liver. Exp Cell Res 266: 177-186.

Warner LE, Mancias P, Butler IJ, McDonald CM, Keppen L, Koob KG, Lupski JR (1998) Mutations in the early growth response 2 (EGR2) gene are associated with hereditary myelinopathies. Nat Genet 18: 382-384.

Whitney MA, Saito H, Jakobs PM, Gibson RA, Moses RE, Grompe M (1993) A common mutation in the FACC gene causes Fanconi anaemia in Ashkenazi Jews. Nat Genet 4: 202-205. 